\title{
Vaccination and autoimmune diseases: is prevention of adverse health effects on the horizon?
}

\author{
Maria Vadalà $^{1,2}$ (D) $\cdot$ Dimitri Poddighe $^{3} \cdot$ Carmen Laurino $^{1,2} \cdot$ Beniamino Palmieri $^{1,2}$
}

Received: 11 May 2017 / Accepted: 31 May 2017 /Published online: 20 July 2017

(C) European Association for Predictive, Preventive and Personalised Medicine (EPMA) 2017

\begin{abstract}
Autoimmune diseases, including multiple sclerosis and type 1 diabetes mellitus, affect about $5 \%$ of the worldwide population. In the last decade, reports have accumulated on various autoimmune disorders, such as idiopathic thrombocytopenia purpura, myopericarditis, primary ovarian failure, and systemic lupus erythematosus (SLE), following vaccination. In this review, we discuss the possible underlying mechanisms of autoimmune reactions following vaccinations and review cases of autoimmune diseases that have been correlated with vaccination. Molecular mimicry and bystander activation are reported as possible mechanisms by which vaccines can cause autoimmune reactions. The individuals who might be susceptible to develop these reactions could be especially not only those with previous post-vaccination phenomena and those with allergies but also in individuals who are prone to develop autoimmune diseases, such as those with a family history of autoimmunity or with known autoantibodies, and the genetic predisposed individuals.

Further research is encouraged into the direct associations between vaccines and autoimmune conditions, and the biological mechanisms behind them.
\end{abstract}

Keywords Vaccine $\cdot$ Predictive preventive personalized medicine $\cdot$ Individualized patient profile $\cdot$ Diabetes $\cdot$ Multiple sclerosis $\cdot$ Genetic test

Maria Vadalà

mary.vadala@gmail.com

1 Department of General Surgery and Surgical Specialties, Medical School, Surgical Clinic, University of Modena and Reggio Emilia, Modena, Italy

2 Network of the Second Opinion, Modena, MO, Italy

3 Department of Pediatrics, ASST Melegnano e Martesana, Milano, Italy

\section{Introduction}

In the twentieth century, the vaccination is the most effective prevention of epidemiologic infectious diseases, such as poliomyelitis, measles, mumps, and rubella [1]. So far, more than 70 vaccines have been licensed on the market against approximately 30 infectious agents: polio, for example, disappeared from the USA by 1979 after widespread vaccination $[2,3]$.

Although the vaccines are generally safe, with a low incidence of serious systemic adverse events, numerous reports highlighted the occurrence of neurological (Guillain Barre syndrome, multiple sclerosis, autism), articular (arthritis, rheumatoid arthritis), and autoimmune untoward effects (systemic lupus erythematosus, diabetes mellitus) after single or combined multivaccine procedures (Table 1) [4].

In the 1994, Stratton and coworkers published the first report on a causal relationship between several vaccines (e.g., diphtheria, tetanus toxoids, oral polio vaccines) and autoimmune disorders (e.g., Guillain-Barre syndrome, type 1 diabetes, and multiple sclerosis) [5].

These autoimmune disorders (rheumatic, endocrinological, and gastrointestinal diseases) are increased significantly over the last 30 years and affect more than $5 \%$ of the individuals worldwide at the age of vaccination programs, which is quite different compared to the spontaneous autoimmune disease incidence [6-9]. These observations raise the problem whether vaccination should be recommended or avoided in autoimmune risk patients [10].

The etiology and the trigger mechanism of autoimmune disease are still unclear [11], but several studies suggest that a vaccine component (inactive viral/bacterial agent or attenuated living microorganism) or a wild superimposed infectious agent can induce autoimmune disease in people with a genetic predisposition [12, 13]. For instance, Borrelia burgdorferi and 
Table 1 Autoimmune diseases reported after vaccination

\begin{tabular}{lll}
\hline Autoimmune disease & Type of vaccine & Ref \\
\hline Systemic lupus erythematosus & HBV, tetanus, anthrax & {$[17]$} \\
Rheumatoid arthritis & HBV, tetanus, typhoid/parathypoid, MMR & {$[18]$} \\
Multiple sclerosis & HBV & {$[19-21]$} \\
Reactive arthritis & BCG, typhoid, DPT, MMR, HBV influenza & {$[22-24]$} \\
Polymiositis/ dermatomyositis & BCG, smallpox, diphtheria, DPT & {$[22,25]$} \\
Polyarteritis nodosa & Influenza, pertussis, HBV & {$[22,25]$} \\
Guillain-Barrè syndrome & Influenza, polio, tetanus & {$[26-28]$} \\
Diabetes mellitus-type I & HIB & {$[29-31]$} \\
Idiopathic thrombocytopenia & MMR, HBV & {$[22,25]$} \\
Hashimoto thyroiditis & HBV & {$[32]$} \\
\hline
\end{tabular}

group A-hemolytic streptococcus contained in the Lyme disease and S. pyogenes vaccines can cause chronic arthritis and rheumatic heart disease, respectively $[14,15]$.

The autoimmune reaction to specific self-antigens can be tissue-specific (such as thyroid, $\beta$-cells of the pancreas), where unique tissue-specific antigens are targeted, or systemic, with multiple tissues affected, and a variety of expressed autoantigens are targeted [2].

The main pathogenic mechanisms of autoimmune disease are the following: (1) Molecular mimicry by which viral or bacterial agents trigger an immune response against autoantigens: the susceptible host is infected by an agent carrying antigens immunologically similar to the host antigens but trigger a different immune response when presented to $\mathrm{T}$ cells. As a result, the tolerance to autoantigens breaks down, and the pathogen-specific immune response causes tissue damage $[11,16]$; (2) Bystander activation by which microbial agents release sequestered self-antigens from host tissue that activate antigen-presenting cells (APCs) and dormant autoreactive T-helper cells. These auto-reactive T cells, along with macrophages, secrete cytokines, and an additive effect results in local inflammation and the recruitment of additional T-helper cells.

We searched, Pubmed/Medline between 1980 and 2016, the issue of immune disorders following vaccination in order to review the state of the art and outline the possible pathogenic link (see Table 1).

\section{Influenza vaccine and Guillain-Barre syndrome}

Guillain-Barré syndrome (GBS) affects the peripheral nerves, with subsequent muscle weakness and loss of reflexes, in 2-8 cases per 100,000 person-years, mainly males [33, 34]. It has been detected after gastrointestinal or upper respiratory tract infections, herpes virus [8], Epstein-Barr virus [9], cytomegalovirus [10], measles [11], and also vaccination; expressing autoimmune antibodies (including against GM1, GD1a,
GT1b, and GQ1b gangliosides) that cross-react with epitopes on peripheral nerves, leading to demyelination and nerve damage [35-38]. Approximately $20-30 \%$ of the cases of GBS is positive to Campylobacter jejuni serologic markers [39, 40]. More rarely Haemophilus influenzae type b (Hib) and respiratory or other microbic infections show an incidence rate of 0.6-4/100,000 person/year worldwide; GBS has been also time related with different vaccines administration, such as rabies, polio, tetanus, Bacillus Calmette-Guerin (BCG), smallpox, mumps, rubella, hepatitis $\mathrm{B}$, and diphtheria [25]. However, the association of GBS and the influenza vaccine is more striking. Nachamkin and coworkers using "swine flu - influenza A (H1N1)" vaccine on 20 mice supposed the responsibility of contaminants, such as sialic acid-hemagglutinin (HA) complexes, or C. jejuni antigens mimicking GM1 ganglioside, leading to the high-titer-specific antibodies after inoculation. In 1976, indeed, the H1N1 vaccination campaign suddenly dropped in the USA due to an increase, within 6 weeks, of 500 cases of GBS (including 25 deaths) over 45 million vaccinated [41]. Laski et al. [27] recorded a $2 \%$ of increase of GBS cases per million vaccinated persons and also in the influenza vaccination program (1992-1993).

Hoshino et al. (2012) reported the first clinical case of acute disseminated encephalomyelitis (ADEM) and GBS associated to H1N1 vaccination in a 36-year-old man [42]. The man developed acute urinary retention, weakness, limbs numbness, and difficulty in walking within 10 days after the vaccine inoculation. Positive anti-GM2 antibodies, which are frequently found in GBS associated with cytomegalovirus infection [43] were detected. Furthermore, Terryberry et al. [44] examined the cerebrospinal fluid (CSF) protein level (normal range $125-150 \mathrm{mg} / \mathrm{L})$ that is always elevated $(>400 \mathrm{mg} / \mathrm{L})$ in GBS patients for the presence of antibodies against 18 myelin autoantigens. These results suggest a multiinfectious etiology of GBS or an increased susceptibility of GBS patients to infection, supposing that GBS is probably both a humoral and a cellular autoimmune disease induced by infection with multiple microorganisms [45]. 
Several mechanisms might explain this outcome: (1) The epitopes of a vaccine could initiate the development of antibodies and/or T cells that could cross-react with epitopes on myelin or axonal glycoproteins; (2) Destruction of the axonal or myelin membranes might be due directly by vaccine virus or vaccine-associated products; (3) Possible genetic susceptibility [42, 46, 47] might be the background. To date, there are no epidemiologic studies that address the question of the risk of GBS development after vaccination, delaying immunization for a short period (e.g., one year) in all the patients with a previous neurological illness is recommended bring some risk (especially after tetanus toxoid) [48].

\section{Influenza vaccine and diabetes}

Type 1 diabetes is an organ-specific autoimmune disease characterized by the selective destruction of pancreatic $\beta$-cells. The pathology shows a decreased $\beta$-cell mass with infiltration of mononuclear cells into Langerhans nests [49].

Currently, around 15 million people, especially young children, are affected and epidemiologic studies evidenced an increase of incidence of type 1 diabetes mellitus in developed countries, among genetically similar populations (e.g. monozygotic twins), supposing that environmental factors play a significant role in the process [50-52].

Observational studies state a temporal link between childhood vaccinations and the development of type 1 diabetes. Supposedly, any vaccination after 2 months age increases the risk of type 1 diabetes but if practiced in the first month of life, it protects against type 1 diabetes [53, 54].

Investigators found a lower incidence of type 1 diabetes in populations immunized with bacille Calmette-Guerin vaccine at birth [55], while others found a higher incidence of the disease in children who received four doses of Hib vaccine at $3,4,6$, and 14 months of age than in those who received one dose of Hib vaccine at 14 months of age [55]. In addition, 21.421 children who received the Hib conjugate vaccine (USA, 1988-1990) were followed for 10 years and the risk of type 1 diabetes development was 0.78 when compared with a group of 22.557 children who did not receive the vaccine [55]. Hviid and coworkers compared the type 1 diabetes incidence in routinely administered childhood vaccines (including Hib, diphtheria, tetanus, poliovirus, pertussis, measles, mumps, and rubella) in a cohort of 740 danish children (born in the range 1990-2000) [56]. Type 1 diabetes was diagnosed in 681 children who received at least one dose of vaccine, as compared with unvaccinated children, with the consequent rate ratio: 0.91 for Hib vaccine; 1.02 for diphtheria, tetanus, and inactivated poliovirus vaccine; 1.06 for whole-cell pertussis vaccine; 1.14 for measles, mumps, and rubella vaccine; and 1.08 for oral poliovirus vaccine. The authors found that the risk of type 1 diabetes increased among children who had one or more siblings with diabetes, supposing also that any association between vaccination and type 1 diabetes would be more pronounced among children who were genetically predisposed to diabetes. Classen and coworkers suggested that the timing of vaccination could be meaningful and that some vaccines, including Hib vaccine might increase the risk of type 1 diabetes if given at age 2 months or older [29, 57]. Nevertheless, this hypothesis was not confirmed by a 10 year follow-up study of more than 100,000 Finnish children involved in a clinical trial of the Hib vaccine [30]. In this study, there was no increased risk of diabetes when children who had received four vaccine doses at 14-18 months, compared with those who received a single dose at 2 years [58-59]. Furthermore, the risk of diabetes did not differ between children in the latter two cohorts and those in a nonconcurrent unvaccinated group.

In Table 2, we reported a summary of epidemiologic studies, reviewed by specific scientific committee, on the association between influenza vaccine and exacerbation of autoimmune disease.

\section{HBV vaccine and multiple sclerosis}

Multiple sclerosis (MS), also known as a "chronic demyelinating inflammatory disease," is an autoimmune disease of the central nervous system (CNS) with myelin destruction in the $\mathrm{CNs}$ or nerve fibers coating sheath. The pathogenic mechanism of MS is supposed to be an overactive or dysfunctional immune response to self-antigen. The activated $\mathrm{T}$ cells induce an inflammatory cascade and cell-mediated attack of CNS myelin [69]. The potential association between the hepatitis B virus (HBV) vaccination and MS development was first recorded at the Hospital Paris (1995-1997) in 35 patients that rose primary demyelinating events, including inflammatory changes in the CSF protein level and lesions in the cerebral white matter on T2-weighted MR images, within 8 weeks of recombinant $\mathrm{HBV}$ vaccine injection [70,71], being the women patients with mean age around 30 years. They were at high MS risk, because all had also over-representation of the HLADR2 antigen and a positive family history of the disease. About 200 cases of CNS demyelinating disorders within 2 months after $H B V$ vaccination were reported to the French pharmacovigilance system [72] and 2 years later, the French government suspended routine immunization of preadolescents in schools [73]. However, these studies were criticized for methodological limitations, including methods used for case ascertainment and control selection, the validation of vaccination status, and limited statistical power, since the findings of two large-scale studies have shown no significant association between $\mathrm{HBV}$ vaccination and the MS occurrence $[74,75]$, but different opinions have also been formulated. For instance, an unpublished study showed by the "capture- 
Table 2: Summary of the epidemiologic studies on relationship between Influenza vaccine and autoimmune diseases

\begin{tabular}{lll}
\hline Type vaccine $\quad$ Study design & Patients & $\begin{array}{l}\text { Findings: primary effect size estimated } \\
\text { (95\% CI or p value) }\end{array}$
\end{tabular}

Studies included in the weight of epidemiologic evidence for Influenza Vaccine and Optic Neuritis

Influenza vaccine Case control study $\quad-108$ patients with optic neuritis

OR for optic neuritis onset any time after

$[60]$

$\begin{array}{ll}\text { Case control study } & -1,131 \text { patients with optic neuritis } \\ & -3,393 \text { controls }\end{array}$ influenza vaccination: $1.2(95 \% \mathrm{CI}$, $0.6-2.3)$

OR for optic neuritis onset within 18 weeks of influenza vaccination: $1.01(95 \% \mathrm{CI}$, $0.79-1.29)$

Studies included in the weight of epidemiologic evidence for Influenza Vaccine and MS Relapse in Adults

Influenza vaccine
Double-blind, randomized controlled trial
Case-crossover controlled study

Studies included in the weight of epidemiologic evidence for Influenza Vaccine and GBS

\begin{tabular}{|c|c|c|}
\hline \multirow[t]{6}{*}{ Influenza Vaccine } & Controlled study & $\begin{array}{l}-12 \text { vaccinated } \\
-393 \text { unvaccinated }\end{array}$ \\
\hline & Controlled study & $\begin{array}{l}\text { 1979-1980 season: } \\
-7 \text { vaccinated }\end{array}$ \\
\hline & & -412 unvaccinated \\
\hline & & 1980-1981 season: \\
\hline & & -12 vaccinated \\
\hline & & -347 unvaccinated \\
\hline
\end{tabular}

Influenza vaccine Self-controlled study

Self-controlled study

Retrospective study
-49 vaccinated

-54 received placebo

-643 patients with definite or probable MS diagnoses

-Three GBS cases in risk period (42 days after vaccine)

-225 GBS cases in control period

-51 GBS cases in risk period (2-7 weeks after vaccine) -141 GBS cases in control period (26-43 weeks after vaccine)

2005-2006: 12 events in risk period; 14.4 events in control period. 2006-2007: 17 events in risk period; 15.1 events in control period 2007-2008: 23 events in risk period; 16.7 events in control period
Significant difference in MS relapse within 28 days or 6 months of influenza vaccination

RR of MS relapse within 2 months of influenza vaccination: 1.08 (95\% CI, 0.37-3.10)

RR of GBS onset within 8 weeks of influenza vaccination: 1.4 (95\% CI, 0.7-2.1)

RR of GBS onset within 8 weeks of vaccination during 1979-1980 season: 0.6 (95\% CI, $0.45-1.32$ ). RR of GBS onset within 8 weeks of vaccination during 1980-1981 season: 1.4 (95\% CI, 0.80-1.76)

Adjusted RR of GBS onset within 42 days of influenza vaccination: 0.99 (95\% CI, $0.32-3.12 ; p=.99$ )

RR of hospitalization for GBS onset during the 2-7 weeks after influenza vaccination: 1.45 (95\% CI, 1.05-1.99)

RR of GBS onset (all ages) 1-42 days after influenza vaccination during the 2005-2006 season: 0.83 RR of GBS onset (all ages) 1-42 days after influenza vaccination during the 2006-2007 season: 1.13 RR of GBS onset (all ages) 1-42 days after influenza vaccination during the 2007-2008 season: 1.37 recapture" method that the real number of MS cases linked to HBV vaccine was 2-2.5 higher than the officially registered number in the French pharmacology. Hernan and coworkers performed a case-control study on 163 MS cases and 1604 matched controls, in the UK within the General Practice Research Database, and found an increased odds ratios (OR) for MS (OR 3.1; CI 1.5-6.3) within the 3 years following $\mathrm{HBV}$ immunization [76]. Another epidemiological case-control study was conducted to evaluate serious post-vaccination adverse events registered in the USA through a spontaneous reporting system in the VAERS database. Adults receiving HBV immunization had significantly increased OR for MS (OR 5.2; CI 1.9-20) in comparison with an age, sex, and vaccine year-matched unexposed tetanus-containing vaccine group [77]. In the same way, a French study on demyelination in childhood [78] showed that Engérix $B \circledR$ vaccine administration was associated with an increased trend of confirmed MS after 3 years (OR 2.77; CI 1.23-6.24). Terney and coworkers described a case report of a female patient (16 years) that has neurological symptoms within 10 weeks after $H B V$ 
immunization [79]. The laboratory assays and brain MRI confirmed acute disseminated encephalomyelitis, collagenosis, sarcoidosis, and a first attack of MS [80]. The patient was treated with immunoglobulin therapy for 10 times $(1 \mathrm{~g} / \mathrm{kg} /$ day) and showed a marked improvement. This report indicates a temporal link between the encephalomyelitis episode and HBV vaccination. The mechanism of this link is unclear, but Faure et al. hypothesize that it is due to molecular mimicry: HBV polymerase (HBV-pol) protein, which could be a contaminant in the recombinant or plasma-derived vaccines, could be co-purified with HBsAg during the manufacturing process, and could act as autoantigen, triggering autoimmune demyelinating disease, such as MS [81].

The controversy between the cited studies suggests the need of further investigations of the relationship between $\mathrm{HBV}$ vaccination and development of MS.

\section{HBV vaccine and systemic lupus erythematosus}

Systemic lupus erythematosus (SLE) is a chronic, multisystemic autoimmune inflammatory disease with multifactorial etiology, including genetic susceptibility, gender differences, and immune system alterations triggered by environmental factors, such as ultraviolet radiation (sunlight) as well as infectious agents, primarily viruses $[82,83]$. SLE mortality and morbidity significantly improved in the last decade, and viral infections have been alleged in the onset or worsening of symptoms of SLE (20-55\%) [84].

Several studies reported the relationship between SLE and HBV vaccine, with statistically significant temporal/causal association, probably due to the low prevalence of postvaccination autoimmunity, low rate of reporting postvaccination adverse events, and various latency periods between vaccination and the onset of disease, as well as atypical presentation of autoimmunity following vaccine [85, 86].

For instance, a case control study of 265 SLE patients and 355 control subjects showed that the $95 \%$ of SLE individuals reported a history of allergy to medications, particularly to antibiotics. There was little association with history of mononucleosis, a marker of late infection with Epstein-Barr virus, implanted medical devices, or hepatitis B vaccination [87].

The first identified SLE case following the HBV vaccine is recorded by Guiserix et al. [88]. A 26-year-old woman presented with fever; cutaneous eruption of the face, arms, and legs; and chills after one week of a first recombinant HBV vaccine (GenHevac-B) dose. The cutaneous biopsy and immunologic tests (antinuclear antibodies, complement component $\mathrm{C} 3$, and $\mathrm{C} 4$ level), carried out 3 months later, confirmed the SLE diagnosis. The authors supposed that $\mathrm{Hb}$ surface antigen protein could play a significant pathogenic role and that the patient with SLE clinical picture should stop the immunization protocol, repeating the antinuclear antibody test 3 months later [89].

Agmon-Levin and coworkers analyzed retrospectively the medical records of 10 SLE patients who developed the disease following HBV vaccination (20\% after the first dose, $20 \%$ after the second dose, and 60\% after the third dose) [90]. The mean latency period from the first HBV immunization and onset of autoimmune symptoms was 56.3 days. The typical SLE manifestations included the joints (100\%), skin $(80 \%)$, muscles (60\%), and photosensitivity (30\%). Seven patients $(70 \%)$ followed the vaccination protocol although a possible autoimmune adverse event was noticed with follow-up period between 1 and 17 years. The clinical findings showed positive ANAs and other autoantibodies in the $90 \%$ of patients, low levels of complement in three of the four examined patients; and elevated cytokine levels [interleukin-2 (IL-2) receptor, interferon-alpha (INFa), and tumor necrosis factor (TNF)] in one patient. Accordingly, with this study, others reported a latency period of several days to 2 years between immunization and the onset of SLE, since the PostHBV vaccine autoimmune conditions can be transient conditions (e.g., vasculitis, arthritis, erythema nodosum) and onset or relapse of a defined disease (e.g., rheumatoid arthritis, multiple sclerosis, SLE) [91].

The cause-and-effect interaction between HBV vaccine and SLE is unclear, although the post-HBV vaccination autoimmunity might be related to an increase in the number of immune complexes as well as to the molecular mimicry between some components of the vaccine (e.g., aluminum, yeast, thimerosal) and self-antigens [92]. This theory is supported by the study of Kowal et al. [93] that proved crossreactivity, at the molecular level, between pneumococcal antibacterial antibodies and generation of antiDNA antibodies, in SLE patients.

Individuals developing a post-vaccination chronic disease are rare when compared with the number of vaccines administered. However, physicians and patients should be encouraged to routinely ask about prior vaccination and report such possible association, as in most countries reporting vaccine adverse events is based on voluntary rather than obligatory notification.

Epidemiologic studies, reported in Table 3, hypothesized that the vaccine could be the precipitating event but these studies did not provide evidence linking these autoimmune diseases to HBV vaccine.

\section{MMR vaccine and idiopathic trombocytopenia}

Another confirmed autoimmune adverse effect associated with vaccination is the induction of idiopathic thrombocytopenia (ITP), also known as immune thrombocytopenia, following the measles-mumps rubella (MMR) vaccine, in 
Table 3: $\quad$ Summary of the epidemiologic studies on relationship between HBV vaccine and autoimmune diseases

\begin{tabular}{lll}
\hline Type vaccine $\quad$ Study design & Patients & $\begin{array}{l}\text { Findings: primary effect size estimated (95\% CI or } \\
\text { p value) }\end{array}$ \\
\hline
\end{tabular}
Studies included in the weight of epidemiologic evidence for HBV Vaccine and Optic Neuritis
HBV vaccine Case control study $\quad-108$ patients with optic neuritis, OR for optic neuritis onset any time after hepatitis B -228 controls
vaccination: 1.2 (95\% CI, 0.5-3.1)
Case control study $\quad-1,131$ patients with optic neuritis, $-3,393$ controls
OR for optic neuritis onset within 18 weeks of hepatitis [61] B vaccination: 1.02 (95\% CI, 0.68-1.54)
[60]

\begin{abstract}
HBV vaccine Case control study $\quad-190$ patients with MS
-534 healthy controls,

HBV vaccine Case control study -332 MS patients, -722 controls

$$
\text { Case control -163 MS patients, }
$$$$
-1,604 \text { controls }
$$

Studies included in the weight of epidemiologic evidence for HBV Vaccine and MS onset in adults
Age-adjusted RR of MS onset any time after hepatitis B [19] vaccination compared to healthy controls: 0.9 (95\% CI, 0.5-1.6)

Age-adjusted RR of MS onset within 2 years of hepatitis $B$ vaccination compared to healthy controls: 0.7 (95\% CI, 0.3-1.7)

-111 breast cancer controls

Age-adjusted RR of MS onset any time after hepatitis B vaccination compared to breast cancer controls: 1.2 (95\% CI, 0.5-2.9)

Age-adjusted RR of MS onset within 2 years of hepatitis $\mathrm{B}$ vaccination compared to breast cancer controls: 1.0 (95\% CI, 0.3-4.2)

OR for MS onset any time after hepatitis B vaccination: [60] 0.8 (95\% CI, $0.5-1.4$

OR for MS onset within 3 years of hepatitis B vaccination: 3.1 (95\% CI, 1.5-6.3)
]

Studies included in the weight of epidemiologic evidence for HBV Vaccine and first demyelinating event in adults

\begin{tabular}{|c|c|c|c|}
\hline \multirow[t]{3}{*}{ HBV vaccine } & Controlled study & $\begin{array}{l}-440 \text { patients with demyelinating disease; } \\
-950 \text { controls }\end{array}$ & $\begin{array}{l}\text { OR for demyelinating disease onset any time after } \\
\text { hepatitis B vaccination: } 0.9(95 \% \mathrm{CI}, 0.6-1.5)\end{array}$ \\
\hline & Controlled study & $\begin{array}{l}-1,131 \text { patients with optic neuritis; } \\
-3,393 \text { controls }\end{array}$ & $\begin{array}{l}\text { OR for optic neuritis onset within } 18 \text { weeks of hepatitis } \\
\text { B vaccination: } 1.02(95 \% \text { CI, } 0.68-1.54)\end{array}$ \\
\hline & Self-controlled study & $\begin{array}{l}-234 \text { patients with a frst CNS demyelinating } \\
\text { event }\end{array}$ & $\begin{array}{l}\text { RR of first demyelinating event } 0-60 \text { days after hepatitis } \\
\text { B vaccination: } 1.68 \text { ( } 95 \% \text { CI, } 0.76-3.68 \text { ). RR of first } \\
\text { demyelinating event } 61-365 \text { days after hepatitis B } \\
\text { vaccination: } 1.33 \text { ( } 95 \% \text { CI, } 0.65-2.69) \text {. RR of first } \\
\text { demyelinating event indefinitely (maximum of } \\
2.29 \text { years) after hepatitis B vaccination: } 1.35 \\
\text { (95\% CI, } 0.61-3.01 \text { ) }\end{array}$ \\
\hline
\end{tabular}

particular within 6 weeks of immunization [95-97]. ITP is an autoimmune condition, clinically characterized by low platelet count (less than 100,000 platelets per microliter) due to increased destruction and impaired platelet production, and by the presence of autoantibodies ( $\mathrm{IgG})$ directed toward platelet membrane antigens (glycoproteins IIb-IIIa) [98]. The main clinical manifestations include various degrees of cutaneous and/or mucosal purpura; life-threatening hemorrhages occur in less than $5 \%$ of adult patients [99]. ITP risk following the MMR vaccine is seen highest in children, aged 12-19 months, which is the estimated age when children would normally be receiving the MMR vaccine.
The development of ITP after the administration of a live attenuated measles vaccine was first described by Oski and Naiman in 1966 [100]. Since then, epidemiological data have clearly demonstrated higher incidence rates of ITP after MMR vaccine, administered alone or in combination [101, 102]; and in 1993, the Vaccine Safety Committee of the Institute of Medicine declared the potential relationship between the MMR vaccine and ITP [103].

Miller and coworkers identified 35 cases (aged 12 to 23 months) of ITP after MMR vaccination and estimated that the attributable risk of ITP within 6 weeks of MMR vaccination is 1 in 32,300 vaccinations [8]. These findings have been 
confirmed in the further case-control study: 23 children (aged 13-24 months) developed ITP after receiving their first MMR dose inoculation, occurring symptoms between day 7 and day 28 after vaccination.

France and coworkers evaluated the risk of ITP after MMR immunization in a large population $(1,036,689$ children, aged 12 months to 18 years) [104]. By using electronic databases, they identified 1673 individuals as potential cases (low platelet count $\leq 50,000 / \mu \mathrm{L})$. Of these, they excluded 532 who had a known cause of thrombocytopenia (e.g., aplastic anemia, leukemia) and 546 who were 30 days of age at the time of diagnosis. These data were similar in magnitude to the results of Miller et al. (IRR: 3.27) and Black et al. (odds ratio: 6.10) $[105,106]$. Furthermore, the authors found a significant association (IRR: 7.1 ) on children aged 12 to 15 months. The hypothesis that MMR-related ITP may be due to a specific immunological mechanism is supported by the recent findings by Okazaki [109] who detected anti-measles and anti-rubella virus IgG antibodies in platelets isolated from a case (aged 15 month) who developed ITP within 4 weeks of the sequential MMR vaccine. The antibodies were found on day 154 of illness when the platelet count was very low but were no longer detectable on day 298 (at the end of the period of thrombocytopenia) or on day 373, when the disease was cured [107]. Some ITP cases that can be negative for antiplatelet antibodies can be due to other mechanisms: here, complementary $\mathrm{T}$ cell immune-mediated destruction or the reduction in the formation of platelets is suspected and with presentation of glycoprotein antigens to APCs, autoantibody generation is stimulated, and ITP can occur [108, 109].

Anyway, the ITP disappears in a few days or weeks in most cases: more than $90 \%$ of children are completely cured within 6 months of diagnosis, and less than $10 \%$ develop chronic disease [110].

In conclusion, although MMR vaccine is associated with an increased ITP risk, the risk is lower compared to the wild viruses, and the clinical picture is less severe. Children with chronic ITP require a more cautious approach: for example, the British Committee for Standards in Haematology advises measuring measles titers before booster administration in order to decide whether a further dose is indicated. If a child has not been previously immunized, the risk-benefit ratio of MMR should be weighed against the risk of measles in the community at the time [111].

\section{MMR vaccine and rheumatoid arthritis}

Rheumatoid arthritis (RA) is a chronic autoimmune disease of unknown etiology, characterized by inflammatory polyarthritis affecting $1 \%$ of the adult population worldwide $[112,113]$. RA is caused by a combination of genetic susceptibility and environmental factors, including not only increased antibody levels of measles virus but also by vaccine strain [114]. A few case reports describe arthritis as a common complication of wild rubella virus in adults, but it occurs less often in children; that in several cases represents the first RA clinical manifestation [115].

Nussinovitich and coworkers (1995) described the first case of acute monoarthritis with effusion in a child (aged 19 months) within 8 days after mumps and measles vaccine, most probably due to the mumps component [116]. The laboratory findings confirmed the following (1) Mumps antibodies (IgG) as measured 1 month later by complement fixation assays were $1 / 64$; (2) Measles antibodies were $1 / 16$ (the titer normally expected after vaccination was $>1 / 8$ ). The patient was treated with intravenous cefuroxime for 5 days, followed by cephalexin by mouth for another 21 days; and his joint symptoms subsided within $24 \mathrm{~h}$.

Another study evaluated the incidence of joint manifestations within 6 weeks after MMR immunization [117]: it included 2658 vaccinated and 2359 non-vaccinated children, confirming an increased risk of joint symptoms (arthralgia or arthritis) in the immunized children.

Symmons et al. [23] suggest three possible explanations to the potential association between immunization and the development of arthritis: (1) it is due to the casual occurrence of two common phenomena: immunization and arthritis; (2) the vaccine activates a specific form of arthritis that is distinct from RA (post-immunization arthritis) and that is usually selflimited; and (3) the vaccine is one of the factors which can trigger the development of RA (so as the infections). A few studies were identified, in the literature, from specific scientific committee to evaluate the risk of autoimmune disease after the administration of MMR vaccine (Table 4).

\section{HPV vaccine and primary ovarian failure}

The HPV vaccines (such as Gardasil® and Cervarix ${ }^{\circledR}$ ) were introduced to fight the cervical cancer; however, several cases of onset or exacerbations of autoimmune diseases following vaccination have been reported [128]. In 2013, Colafrancesco reviewed three women (two of them are sisters, thus bringing the relevance of genetics linkage) that developed primary ovarian failure within 2 years by HPV vaccine [129]. All the patients developed secondary amenorrhea, low estradiol, and high follicle-stimulating hormone (FSH) and luteinizing hormone (LH) following HPV vaccination, and elevated antiantibodies levels (e.g., anti-thyroid antibodies and antiovarian antibodies). The authors suggested that the use of adjuvants in the HPV vaccine could be a risk factor for eliciting an autoimmune reaction to the vaccination: the DNA fragments detected in 16 different Gardasil@ vaccines appeared to be bound to the aluminum used in the vaccine formulation. 
Table 4: Summary of the epidemiologic studies on relationship between MMR vaccine and autoimmune diseases

\begin{tabular}{|c|c|c|c|}
\hline Type vaccine & Study design & Patients & $\begin{array}{l}\text { Findings: primary effect size estimated (95\% CI } \\
\text { or p value) }\end{array}$ \\
\hline
\end{tabular}

Studies included in the weight of epidemiologic evidence for MMR Vaccine and transient arthralgia in women and children

MMR vaccine Retrospective study - 485 vaccinated women;

- 493 unvaccinated women

Double-blind, randomized controlled trial

-268 vaccinated, -275 received placebo

Retrospective study

-971 seronegative, vaccinated women,

$-2,421$ seropositive, unvaccinated, aged-matched controls;

-924 seronegative, unvaccinated, unmatched controls

Double-blind, randomized, controlled trial

MMR vaccine

Double-blind, controlled crossover study

Presence of Dominican Republic-2 (DR2) virus:

41 vaccinated;

38 received placebo

581 twin pairs

Double-blind, controlled crossover study

581 twin pairs, separated into two age groups: 14-18 months and 6 years of age

Double-blind, randomized control trial
2,216 vaccinated with MMR II, 3,521 unvaccinated

Case-control
Maximum difference rate of arthropathy between MMR vaccine and placebo groups at 7-9 days after vaccination: $0.8 \%$ (95\% CI, $0.2-1.3 \%$ )

Vaccinated: 4 cases of arthralgia $(0.8 \%)$.

Unvaccinated: 3 cases of arthralgia

$(0.6 \%)$. Differences were not

statistically significant

Acute arthralgia or arthritis within 12 months of rubella vaccination: 1.73 (95\% CI, $1.17-2.57)$

Vaccinated: 4 patients diagnosed as acute arthralgias cases and 1 as indeterminate, seropositive, unvaccinated.

Controls: one acute event

Acute arthralgia or arthritis within 12 months of rubella vaccination in women expressing DR2: 4.8 (95\% CI, 1.2-18.8)

Adjusted OR of arthralgia in the 14-18 month age group within 21 days of MMR vaccination: 3.66 (95\% CI, 1.74-7.70)

MMR II group: 8 joint reactions (primarily transient arthralgia) within 30 days of vaccination

OR for psoriatic arthritis after rubella vaccination: 12.4 (95\% CI, 1.20-122.14)
125 patients with psoriatic arthritis; 163 patients with psoriasis

Studies included in the weight of epidemiologic evidence for MMR Vaccine and Type 1 Diabetes

MMR vaccine Case-control

Case-control

Retrospective cohort
-393 children with type 1 diabetes; -786 controls matched on age, sex, and county

-136 children with type 1 diabetes; -272 controls matched on age and registration with the same family pediatrician

739,694 children
OR for type 1 diabetes diagnosis; any time after MMR vaccination: 0.95 (95\% CI, 0.71-1.28) OR for type 1 diabetes diagnosis any time after measles vaccination: 0.74 (95\% CI, 0.55-1.00) OR for type 1 diabetes diagnosis any time after mumps vaccination: 1.75 (95\% CI,

$0.54-5.70)$. OR for type 1 diabetes diagnosis any time after rubella vaccination: 1.24 (95\% CI,0.41-3.73)

OR for type 1 diabetes diagnosis any time after MMR vaccination: 0.382 (95\% CI, 0.201-0.798) OR for type 1 diabetes diagnosis any time after measles vaccination: 0.777 (95\% CI, 0.403-1.498)

Rate ratio for type 1 diabetes diagnosis any time after one dose of MMR vaccine compared to the unexposed: 1.14 (95\% CI, 0.90-1.45) 


\section{HPV vaccine and SLE}

In 2013, Gatto and coworkers investigated cases of SLE in women following HPV vaccination [130]. The onset of SLE occurred during the later doses of the HPV vaccination schedule and all the women had family histories of autoimmune disease. The major remitting patients with immunosuppression therapy had mild adverse effects to the vaccine immediately following the first dose of the HPV vaccine and then developed heavier SLE symptoms within two months after subsequent vaccine administration. In conclusion, the authors hypothesized a potential causal link between HPV vaccination and onset or relapse of SLE [130]. Thus, although for most patients, the benefits of immunization outweigh its risks, clinicians must be aware of the odds for an autoimmune disease onset or exacerbation following HPV vaccination. A meticulous pre-vaccination risk-benefits assessment, close followup during and after each boost of vaccination, as well as assessment of concomitant therapy with immune-modulating agents such as hydroxychloroquine (HCQ), seems reasonable for patients with an autoimmune disease. In 2013, Macartney and colleague reviewed the literature of HPV vaccine-related adverse effects and they reported almost mild reaction such as local injection site swelling with local or generalized pain [131]. Subjective reports are the primary source of vaccine adverse event but a systematic approach to track vaccination morbidity is required. In addition, the short follow-up institutionally fixed by the health authorities miss mild and severe long-term adverse reactions and large genetically different vaccinated group would better outline the problem. Thus, long-term surveillance of vaccines among interethnic populations groups would define more accurately their safety.

\section{HPV vaccine and ASIA syndrome}

Recently, several reports have suggested grouping different autoimmune conditions that are triggered by external stimuli (e.g., exposure to vaccine) as a single syndrome called autoimmune syndrome induced by adjuvants (ASIA) [132]. This syndrome is characterized by the appearance of myalgia, myositis, muscle weakness, arthralgia, arthritis, chronic fatigue, sleep disturbances, cognitive impairment, and memory loss. This term was introduced by Yehuda Shoenfeld, who highlighted the pathogenic role of adjuvants in the induction of autoimmune syndromes: these compounds mimic evolutionarily conserved molecules (e.g., bacterial cell walls, LPS, unmethylated $\mathrm{CpG}-\mathrm{DNA}$ ) and bind to toll-like receptors (TLRs). They activate dendritic cells (DCs), lymphocytes, and macrophages, increasing subsequently the release of chemokines and cytokines from T-helper and mast cells [133-137]. The adjuvants added into vaccines can induce a non-specific activation of the immune system with a subsequent expansion of autoreactive (in our case, myelin specific) lymphocytes that may be further accelerated by defective regulatory cells/circuits, in genetically susceptible individuals. Indeed, the main individuals at ASIA syndrome risk are as follows: (1) patients with prior post-vaccination autoimmune phenomena, (2) patients with a medical history of autoimmunity, (3) patients with a history of allergic reactions, and individuals who are prone to develop autoimmunity (having a family history of autoimmune diseases, presence of autoantibodies, carrying certain genetic profiles, etc.) [138].

In the 2016, we retrospectively described a case series including 18 girls (aged 12-24 years) for the evaluation of "neuropathy with autonomic dysfunction" immediately after HPV vaccine [Gardasil ${ }^{\circledR}\left(9\right.$ girls) and Cervarix ${ }^{\circledR}(9$ girls)] [139]. All girls complained of long-lasting and invalidating somatoform symptoms of the recently described ASIA syndrome (including asthenia, headache, cognitive dysfunctions, myalgia, sinus tachycardia, and skin rashes) that have developed 1-5 days ( $n=11), 5-15$ days $(n=5)$, and 15-20 days $(n=2)$ after the last dose vaccination. The HPV vaccine formula contains aluminum $(225$ e $500 \mu \mathrm{g} /$ each dose in Gardasil ${ }^{\circledR}$ and Cervarix $®$, respectively) but also high polysorbate $80(50 \mathrm{mcg})$ concentration that might also induce a greater meningeal permeability leading to a facilitated entrance of many substances to the CNS. Based upon these observations, it might be speculated that HPV vaccine could induce some abnormal activation of immune competent cells in the CNS, such as the glia.

Among the risk factors for ASIA syndrome, the metal hypersensitivity in girls, mainly genetically predisposed individuals, exposed to immunization, has been suspected. We tested five adjuvant metals (aluminum, mercury, nickel, methylmercury, thimerosal) in our case series through in vitro blood test and lymphocyte transformation test (MELISA ${ }^{\circledR}$ ). However, the study was frustrating, being the seven girls negative to each of the five metals tested, showing a metalhypersensitivity only in nine patients: toxicity to aluminum (two girls), reactivity to nickel (seven girls), followed by mercury (four girls) [140].

Case control and epidemiological studies and a detailed genetic analysis of affected girls and their family might better define the link between vaccination and CNS damage.

\section{HPV Vaccine and transverse myelitis}

Transverse myelitis (TM) is the paradigm of inflammatory myelopathy, in which an immune-mediated process causes neural injury to the spinal cord, resulting in varying degrees of weakness, sensory alterations, and autonomic dysfunction. TM may exist as part of a multifocal central nervous system disease (e.g., multiple sclerosis), multisystemic disease (e.g., SLE), or as an isolated idiopathic entity [141]. A recent review 
(2014) summarizes nine published cases of CNS demyelination, including not only myelitis but also optic neuritis and encephalitis, following HPV vaccination [142]. There are previous reports of CNS inflammatory syndromes following HPV vaccination describing a 10-day to 5-month time lapse from vaccination to symptom onset, with a minimum of a 21 day interval in cases developing myelitis. For instance, a 14year-old immunocompetent girl noticed her left hand felt weak and numb, after 3 days of a first dose of HPV vaccine (Gardasil@) and these symptoms spread to the rest of her arm and ipsilateral thoracic region, abdomen, and leg. On a medical examination, the girl had bilateral diminished sensation to light touch, pain, and vibration below C5 level; muscle weakness of her left arm and leg; and hyperreflexia bilaterally with nonsustained clonus and a left extensor plantar response. Neurologic examination was otherwise normal. The relationship between HPV vaccination and subsequent CNS inflammation remains unclear. In the genesis of CNS inflammatory disorders post-HPV vaccination, both molecular mimicry between vaccine antigen and myelin proteins and toxic materials in vaccine components can represent potential causative factors [143]. Regarding etiology, the patient was immunocompetent and there were no systemic signs of infection. The absence of cells in CSF analysis and the presence of oligoclonal bands with an increased nonspecific immunoglobulin $\mathrm{M}$ ratio suggested a background of a CNS inflammatory condition; however, the mechanism of disease, whether viralinduced or immune-mediated, remains to be determined.

\section{Genetic basis for autoimmune diseases following vaccination}

Several studies identified genetic variants of the human leukocyte antigen (HLA) gene family, significantly associated with vaccine-induced autoimmune activation; some of these HLA variants include HLA DRB1, HLA DRB2, HLA DR4, HLA and DRQ8 that are implicated in autoimmune processes, such as detection and removal of antigens during infection [144-146].

A significant study, conducted in 2008, found statistical correlations between six genetic variants [three variants of interleukin 4 (IL4), two variants of interferon regulatory factor (IRF1), and one variant of methylenetetrahydrofolate reductase (MTHFR), the C677T allele] and adverse event vaccine following smallpox vaccine [147].

IL4 is an anti-inflammatory cytokine involved in the cellmediated inflammatory immune response, including inhibition of monocyte and dendritic cell migration to inflamed tissue and promotion of Th2 effector pathways [148, 149]. CD4+ T cell differentiation away from the Th1 pathway renders them unable to activate macrophages. Upon immunological challenge by vaccination, the differentiation of CD4+ T cells into armed Th1 versus Th2 cells plays a vital role in determining whether the adaptive immune response will be dominated by humoral effectors or macrophage activation [150]. Thus, genetic polymorphisms related to inappropriate regulation of IL-4 expression and/or activity of IL-4 cytokine may over-stimulate inflammatory responses, leading to the development of adverse events. IL-4 dysregulation may also play a role in AEs resulting from the inappropriate clearance of apoptotic immune effector cells after infection, as this function is normally carried out by macrophages.

IRF1 is a transcription factor involved in the release of cytotoxic interferon, and cell apoptosis; it may push macrophage activity beyond the threshold of AE development [151]. Hyperactive IRF1 may also prolong the life of immune cells that should be cleared following infection, protracting the period of inflammation and leading to AEs.

The MTHFR 677 variant has been associated with many phenotypes, including cardiovascular function, transplant health, toxicity of immunosuppressive drugs, and systemic inflammation [152, 153]. Elevated plasma homocysteine levels stimulate endothelial inflammatory responses, which could contribute to adverse events. Alternatively, since vaccination elicits 109 immune responses involving the rapid proliferation of cells, demand for DNA synthesis metabolites would be elevated, and alterations in the level or activity of MTHFR enzyme may exert significant influence over this process.

The results of this study evidence the utility of validation in genetic studies of complex phenotypes. As with any statistical association, follow-up studies are needed to identify the particular genetic susceptibility variants and examine the functional consequences of polymorphisms in the AE-associated genes. Since the authors found multiple AE-associated SNPs in regions of IL-4 and IRF1, focused studies should be undertaken to characterize the genetic variability in these candidate regions. While the association of AEs with a non-synonymous polymorphism in the gene 113 for MTHFR points toward functional significance of this SNP, deep resequencing should determine whether this is indeed the case. For all three candidate genes, functional studies are needed to connect genetic polymorphisms to AEs following immunization.

\section{Discussion}

Most of the studies on vaccine-related adverse events reduce to a 10-20 day follow-up analysis, the recruitment of putatively linked autoimmune events. The analysis of potential correlation between vaccine and autoimmune events/diseases is puzzling, being not-specific and without a clear cut diagnosis, not excluding other contemporary virus infections, environmental factors, or nutrition imbalance. The adjuvants (e.g., aluminum, thimerosal) in vaccines were related to 
Table 5 A summary of the epidemiologic assessments and causality conclusions for hepatitis A vaccine

\begin{tabular}{|c|c|c|c|c|}
\hline $\begin{array}{l}\text { Type } \\
\text { vaccine }\end{array}$ & Adverse event & $\begin{array}{l}\text { Epidemiologic } \\
\text { assessment }\end{array}$ & $\begin{array}{l}\text { Studies contributing } \\
\text { to epidemiologic } \\
\text { assessment }\end{array}$ & $\begin{array}{l}\text { Causality } \\
\text { conclusion }\end{array}$ \\
\hline \multirow{5}{*}{$\begin{array}{l}\text { Hepatitis A } \\
\text { vaccine }\end{array}$} & Transverse myelitis & Insufficient & None & Inadequate \\
\hline & MS & Insufficient & None & Inadequate \\
\hline & Guillain-Barré syndrome & Insufficient & None & Inadequate \\
\hline & $\begin{array}{l}\text { Chronic inflammatory disseminated } \\
\text { polyneuropathy }\end{array}$ & Insufficient & None & Inadequate \\
\hline & Autoimmune hepatitis & insufficient & None & Inadequate \\
\hline
\end{tabular}

autoantibodies levels, such as raised anticardiolipin antibodies after influenza vaccination in patients with lupus, antiEpstein-Barr antibodies after HPV vaccine [139, 154-156]. The adjuvants enhance and prolong the immune response, promoting physical protection against the pathogen and facilitating its translocation to lymph nodes [157]. The development of an inactivated vaccine would be a solution for the immunosuppressed individuals. However, killed vaccines may have disadvantages as risk of incomplete inactivation, change in immunogenic properties of the virus, and the use of multiple doses $[158,159]$. The relationship between vaccines and autoimmunity is bidirectional. On the one hand, the immunization prevents infectious diseases, and thus in turn prevents the development of an overt autoimmune disease which in some individuals is triggered by infections. Furthermore, Singh et al. [160] suggest that immunization with certain vaccines may stimulate the immune system to modulate or prevent the generation of pathogenic cells by the induction of regulatory cells, and thus prevent autoimmunity. The post-vaccination adverse events strongly suggest that vaccinations can trigger autoimmunity in a similar way to the infections to be prevented. In this way, vaccination should be considered as part of the mosaic of autoimmunity, in which abrogation of an autoimmune disease (and in the case of vaccination, the prevention of an autoimmune disease) could concomitantly induce another autoimmune disease.

During the vaccination process, only a comprehensive and multidisciplinary strategy can help to reduce the risk that a new one will induce autoimmune reactions: (1) the question whether clinical manifestations of an autoimmune nature are known to be associated with the infectious disease that will be the target of the new vaccine has to be raised. If such events have been
Table 6 A summary of the epidemiologic assessments and causality conclusions for hepatitis $B$ vaccine

\begin{tabular}{|c|c|c|c|c|}
\hline $\begin{array}{l}\text { Type } \\
\text { vaccine }\end{array}$ & Adverse event & $\begin{array}{l}\text { Epidemiologic } \\
\text { assessment }\end{array}$ & $\begin{array}{l}\text { Studies contributing } \\
\text { to epidemiologic } \\
\text { assessment }\end{array}$ & $\begin{array}{l}\text { Causality } \\
\text { conclusion }\end{array}$ \\
\hline \multirow{15}{*}{$\begin{array}{l}\text { Hepatitis B } \\
\text { vaccine }\end{array}$} & Transverse myelitis & Insufficient & None & inadequate \\
\hline & Optic neuritis & Limited & 2 & Inadequate \\
\hline & MS onset in adults & Limited & 4 & Inadequate \\
\hline & MS onset in children & Limited & 1 & Inadequate \\
\hline & MS relapse in adults & Limited & 1 & Inadequate \\
\hline & MS relapse in children & Limited & 1 & Inadequate \\
\hline & $\begin{array}{l}\text { First demyelinating event in } \\
\text { adults }\end{array}$ & Moderate & 3 & Inadequate \\
\hline & $\begin{array}{l}\text { First demyelinating event in } \\
\text { children }\end{array}$ & Limited & 1 & Inadequate \\
\hline & Guillain-Barré syndrome & Insufficient & None & Inadequate \\
\hline & Chronic Inflammatory & Insufficient & None & Inadequate \\
\hline & Disseminated & & & \\
\hline & Polyneuropathy & & & \\
\hline & $\begin{array}{l}\text { Onset or exacerbation of } \\
\text { rheumatoid arthritis }\end{array}$ & Limited & 1 & Inadequate \\
\hline & Type 1 diabetes & Moderate & 1 & Inadequate \\
\hline & Fibromyalgia & Insufficient & None & Inadequate \\
\hline
\end{tabular}


Table 7 A summary of the epidemiologic assessments, mechanistic assessments, and causality conclusions for influenza vaccine

\begin{tabular}{|c|c|c|c|c|}
\hline $\begin{array}{l}\text { Type } \\
\text { vaccine }\end{array}$ & Adverse event & $\begin{array}{l}\text { Epidemiologic } \\
\text { assessment }\end{array}$ & $\begin{array}{l}\text { Studies contributing to } \\
\text { epidemiologic assessment }\end{array}$ & $\begin{array}{l}\text { Causality } \\
\text { conclusion }\end{array}$ \\
\hline \multirow{6}{*}{$\begin{array}{l}\text { Influenza } \\
\text { vaccine }\end{array}$} & Transverse myelitis & Insufficient & None & inadequate \\
\hline & Optic neuritis & Limited & 2 & Inadequate \\
\hline & MS onset in adults & Limited & 2 & Inadequate \\
\hline & Guillain-Barré Syndrome & Moderate & 9 & Inadequate \\
\hline & $\begin{array}{l}\text { Chronic inflammatory } \\
\text { disseminated } \\
\text { polyneuropathy }\end{array}$ & Insufficient & None & Inadequate \\
\hline & Fibromyalgia & Insufficient & None & Inadequate \\
\hline
\end{tabular}

reported, e.g., for group A streptococcal diseases, attention should be given to avoid reproducing the natural pathogenic process; this process might include the identification and exclusion of naturally pathogenic epitopes; (2) potential molecular and immunological mimicry between vaccine antigens and host components should be extensively analyzed through a combination of bioinformatics and immunological studies. Information should be gathered on the relative ability of such epitopes to bind to MHC molecules, to be processed by antigen-presenting cells, and to be recognized by autoreactive $\mathrm{T}$ cells. Molecular mimicry in itself is not sufficient to trigger autoimmune pathology, and other factors intrinsic to infections, such as tissue damage and long-lasting inflammatory reaction, might be required as well. For example, a new Lyme disease vaccine contains an immunodominant epitope of the outer surface protein A of Borrelia burgdorferi that displays great homology to human lymphocyte function-associated antigen-1, an adhesion molecule of the two integrin family [161]. Although this homology raised concern about the safety of this vaccine, there was no evidence for an increased frequency of arthritis in individuals who received the Lyme vaccine [162]; (3) indicative information can be obtained through the use of ad hoc experimental models of autoimmune diseases. Different vaccine formulations and adjuvants can be compared with respect to their potential capacity to induce or enhance the expression of pathology in relevant models; (4) appropriate immunological investigations, e.g., autoimmune serology, can be systematically included in phase I-III clinical trials.

In conclusion, clinical surveillance of potential autoimmune adverse effects and appropriate laboratory tests should be considered for inclusion in the monitoring protocol. Such surveillance should be extended through the postmarketing stage if specific rare events have to be ruled out [10].

Reports on autoimmune reactions after vaccination would constitute probably less than $0.01 \%$ of all vaccinations performed worldwide, although this rate may be biased by underreporting.

We reported a summary of epidemiologic assessments, and causality conclusions for the main vaccines described in this review, including hepatitis $A$, hepatitis $B$, influenza, MMR, HPV vaccine (Tables 5, 6, 7, 8, and 9).

In addition, many of those reactions are mild and self-limited. Nevertheless, we should be cautious, especially not only in cases

Table 8 A summary of the epidemiologic assessments, mechanistic assessments, and causality conclusions for MMR vaccine

\begin{tabular}{|c|c|c|c|c|}
\hline Type vaccine & Adverse event & Epidemiologic assessment & $\begin{array}{l}\text { Studies contributing } \\
\text { to epidemiologic assessment }\end{array}$ & Causality conclusion \\
\hline \multirow{9}{*}{$\begin{array}{l}\text { MMR } \\
\text { vaccine }\end{array}$} & Transverse myelitis & Insufficient & None & Inadequate \\
\hline & Optic neuritis & Limited & 1 & Inadequate \\
\hline & MS onset in adults & Limited & 2 & Inadequate \\
\hline & MS onset in Children & Limited & 1 & Inadequate \\
\hline & Guillain-Barré Syndrome & Insufficient & None & Inadequate \\
\hline & $\begin{array}{l}\text { Chronic Inflammatory } \\
\text { Disseminated } \\
\text { Polyneuropathy }\end{array}$ & Insufficient & None & Inadequate \\
\hline & Chronic arthritis in Women & Limited & 2 & Inadequate \\
\hline & Type 1 Diabetes & High & 5 & Favors rejection \\
\hline & Fibromyalgia & Insufficient & None & Inadequate \\
\hline
\end{tabular}


Table 9 A summary of the epidemiologic assessments, mechanistic assessments, and causality conclusions for HPV vaccine

\begin{tabular}{|c|c|c|c|c|}
\hline $\begin{array}{l}\text { Type } \\
\text { vaccine }\end{array}$ & Adverse event & $\begin{array}{l}\text { Epidemiologic } \\
\text { assessment }\end{array}$ & $\begin{array}{l}\text { Studies contributing to } \\
\text { epidemiologic assessment }\end{array}$ & $\begin{array}{l}\text { Causality } \\
\text { conclusion }\end{array}$ \\
\hline \multirow{7}{*}{$\begin{array}{l}\text { HPV } \\
\text { vaccine }\end{array}$} & Transverse myelitis & Insufficient & None & Inadequate \\
\hline & Neuromyelitis optica & Insufficient & None & Inadequate \\
\hline & MS & Insufficient & None & Inadequate \\
\hline & $\begin{array}{l}\text { Guillain-Barré } \\
\text { syndrome }\end{array}$ & Insufficient & None & Inadequate \\
\hline & $\begin{array}{l}\text { Chronic inflammatory } \\
\text { disseminated } \\
\text { polyneuropathy }\end{array}$ & Insufficient & None & Inadequate \\
\hline & $\begin{array}{l}\text { Amyotrophic lateral } \\
\text { sclerosis }\end{array}$ & insufficient & None & Inadequate \\
\hline & Transient arthralgia & limited & 1 & Inadequate \\
\hline
\end{tabular}

with previous post-vaccination phenomena and those with allergies but also in individuals who are prone to develop autoimmune diseases, such as those with a family history of autoimmunity or with known autoantibodies, and in genetic predisposed individuals. In such subsets, the potential benefit of vaccination should be weighed against its potential risk [138].

In the 2015, Soriano et al. supposed that four groups of individuals are at risk: (1) patients with prior postvaccination autoimmune phenomena, such as patients who showed initial clinical manifestations (fever, arthralgia) after dose vaccination; (2) immunosuppressed patients with autoimmune conditions: indeed, live vaccines including BCG, MMR vaccines, and vaccines against herpes zoster, and yellow fever are generally contraindicated in these patients due to the risk of an uncontrolled viral replication [163]; (3) patients with a history of allergic reactions: the vaccine components include potential allergens such as animal-derived proteins like egg (present in yellow fever, influenza, and MMR vaccines), adjuvants like aluminum (present in HPV, HNI, and HBV and vaccines) and thimerosal (HPV vaccine), antibiotics like gentamycin, neomycin, streptomycin, polymyxin B, and stabilizers like gelatin (present in varicella, and MMR vaccines) and lactose; (4) patients who are prone to develop autoimmunity, including patients having a family history of autoimmune diseases; asymptomatic carriers of autoantibodies, such as high levels of anti-citrullinated protein antibodies (ACPA) in RA, anti-mitochondrial antibodies (AMA) in primary biliary cirrhosis, anti-thyroid antibodies in Hashimoto's thyroiditis, and anti-dsDNA in SLE [164]; carrying certain genetic profiles, including patients with polymorphisms associated with the insulin gene, the thyroglobulin gene and the thyroid-stimulating hormone receptor gene [165].

\section{Conclusions and expert recommendations}

The vaccination might display autoimmune side effects and potentially even trigger a full-blown autoimmune disease. This susceptibility to vaccine-induced autoimmunity is probably determined also by genetic predisposition, which further emphasizes the importance of "the mosaic of autoimmunity" [4]. The vaccination decreases the morbidity and mortality of the individuals, especially children. Nevertheless, the dilemma of whom and when to vaccinate remains unresolved and further research is needed to explain the action mechanism.

Finally, we believe that our commitment should be to plan genetic investigations on the post-vaccination autoimmune-affected patients in order to clarify the pathogenic background and the physiopathology of vaccine-related autoimmune response. Hopefully, this approach might lead to outline a screen-test (patch test?) for this risk and, eventually, to prevention of adverse reactions by vaccination. It could represent a "personalized medicine" that could potentially improve preventive methods and therapeutic options, accordingly with the recommendations of the "European Association for Predictive, Preventive and Personalised Medicine" [166].

\section{Compliance with ethical standards}

Funding This study is not funded.

Conflict of interest The authors declare that they have no conflict of interest.

\section{References}

1. Nabel GJ. Designing tomorrow's vaccines. N Engl J Med. 2013;368(6):551-60.

2. Ansakorpi H, et al. Lambert-Eaton myasthenic syndrome following H1N1-influenza vaccination: a case report. Acta Neurol Scand. 2012;126(5):e25-8.

3. Beeler J, Varricchio F, Wise R. Thrombocytopenia after immunization with measles vaccines: review of the vaccine adverse events reporting system (1990 to 1994). Pediatr Infect Dis J. 1996;15(1):88-90. 
4. Shoenfeld Y, Aharon-Maor A, Sherer Y. Vaccination as an additional player in the mosaic of autoimmunity. Clin Exp Rheumatol. 2000;18(2):181-4.

5. Stratton KR, Howe CJ, Johnston RB Jr. Adverse events associated with childhood vaccines other than pertussis and rubella. Summary of a report from the Institute of Medicine. JAMA. 1994;271(20):1602-5.

6. Jacobson DL, Gange SJ, Rose NR, Graham NM. Epidemiology and estimated population burden of selected autoimmune diseases in the United States. Clin Immunol Immunopathol. 1997;84(3):223-43.

7. Onkamo P, Väänänen $\mathrm{S}$, Karvonen $\mathrm{M}$, Tuomilehto J. Worldwide increase in incidence of type I diabetes - the analysis of the data on published incidence trends. Diabetologia. 1999;42(12):1395-403.

8. Variation and trends in incidence of childhood diabetes in Europe. EURODIAB ACE Study Group. Lancet. 2000;355(9207):873-6.

9. Lerner A, Jeremias P, Matthias T. The world incidence and prevalence of autoimmune diseases is increasing. Int J Celiac Dis. 2015;3(4):151-5.

10. Wraith DC, Goldman M, Lambert PH. Vaccination and autoimmune disease: what is the evidence? Lancet. 2003;362(9396):1659-66.

11. Albert LJ, Inman RD. Molecular mimicry and autoimmunity. N Engl J Med. 1999;341(27):2068-74.

12. Langridge WH. Edible vaccines. Sci Am. 2000;283(3):66-71.

13. Todd JA, Wicker LS. Genetic protection from the inflammatory disease type 1 diabetes in humans and animal models. Immunity. 2001;15(3):387-95.

14. Steere AC, et al. Lyme arthritis: an epidemic of oligoarticular arthritis in children and adults in three Connecticut communities. Arthritis Rheum. 1977;20(1):7-17.

15. Zabriskie JB, Freimer EH. An immunological relationship between the group. A streptococcus and mammalian muscle. J Exp Med. 1966;124(4):661-78.

16. Regner M, Lambert PH. Autoimmunity through infection or immunization? Nat Immunol. 2001;2(3):185-8.

17. Tudela P, Marti S, Bonal J. Systemic lupus erythematosus and vaccination against hepatitis B. Nephron. 1992;62(2):236.

18. Symmons DP, Chakravarty K. Can immunisation trigger rheumatoid arthritis? Ann Rheum Dis. 1993;52(12):843-4.

19. Ascherio A, et al. Hepatitis B vaccination and the risk of multiple sclerosis. N Engl J Med. 2001;344(5):327-32.

20. Tourbah A, et al. Encephalitis after hepatitis B vaccination: recurrent disseminated encephalitis or MS? Neurology. 1999;53(2):396-401.

21. Contavreux C, Suissa S, Saddier P, Bourdes V, et al. Vaccination and the risk of relapse in multiple sclerosis. N Engl J Med. 2001;344:319-26.

22. Aharon-Maor A, Shoenfeld Y. The good, the bad and the ugly of vaccination. Isr Med Assoc J. 2000;2(3):225-7.

23. Symmons DP, Chakravarty K. Can immunization trigger rheumatoid arthritis. Ann. Rheum. Dis. 1993;52:843-4.

24. Tishler M, Shoenfeld Y. Vaccination may be associated with autoimmune diseases. Isr Med Assoc J. 2004;6:430-2.

25. Schonberger LB, Bregman DJ, Sullivan-Bolyai JZ, Keenlyside RA, Ziegler DW, Retailliau HF, et al. Guillain-Barre syndrome following vaccination in the National Influenza Immunization Program, United States, 1976-1977. Am J Epidemiol. 1979;110(2):105-23.

26. Shoenfeld Y, Aron-Maor A. Vaccination and autoimmunity'vaccinosis': a dangerous liaison? J Autoimmun. 2000;14:1-10.

27. Lasky T, Magder TG. The Guillain-Barre syndrome and the 19921993 and 1993-1994 influenza vaccines. N Engl J Med. 1998;339: 1797-801.

28. Geier MR, Geier DA, Zahalsky AC. Influenza vaccination and Guillain Barre syndrome. Clin Immunol. 2003;107(2):116-21.

29. Classen JB, Classen DC. Association between type I diabetes and Hib vaccine: causal relation is likely. BMJ. 1999;319:1133.
30. Karvonen M, Cepaitis Z, Tuomilehto J. Association between type 1 diabetes and Haemophilus influenzae type $b$ vaccination: birth cohort study. BMJ. 1999;318:1169-72.

31. Wakeberg J, Fredriksson J, Vaarala O, Ludvigsson J. Vaccinations may induce diabetes-related autoantibodies in one-year-old children. Ann N Y Acad Sci. 2003;1005:404-8.

32. Yu O, Bohlke K, Hanson CA, Delaney K, Rees TG, Zavitkovsky A, et al. Hepatitis B vaccine and risk of autoimmune thyroid disease: a vaccine safety datalink study. Pharmacoepidemiol Drug Saf. 2007;16(7):736-45.

33. Sejvar JJ, Baughman AL, Wise M, Morgan OW. Population incidence of Guillain-Barre syndrome: a systematic review and metaanalysis. Neuroepidemiology. 2011;36(2):123-33.

34. Shui IM, Rett M, Weintraub E, Marcy M, Amato AA, Sheikh SI, et al. Vaccine safety datalink research team. Guillain-Barré syndrome incidence in a large United States cohort (2000-2009). Neuroepidemiology. 2012;39(2):109-15.

35. Lehmann HC, Hartung HP, Kieseier BC, Hughes RA. GuillainBarre syndrome after exposure to influenza virus. Lancet Infect Dis. 2010;10(9):643-51.

36. Tam CC, O'Brien SJ, Petersen I, Islam A, Hayward A, Rodrigues LC. Guillain-Barre syndrome and preceding infection with campylobacter, influenza and Epstein-Barr virus in the general practice research database. PLoS One. 2007;2(4):e344.

37. Stowe J, Andrews N, Wise L, Miller E. Investigation of the temporal association of Guillain-Barre syndrome with influenza vaccine and influenza like illness using the United Kingdom General Practice Research Database. Am J Epidemiol. 2009;169(3):382-8.

38. Hardy TA, Blum S, McCombe PA, Reddel SW. Guillain-Barr syndrome: modern theories of etiology. Curr Allergy Asthma Rep. 2011;11(3):197-204.

39. McCarthy N, Giesecke J. Incidence of Guillain-Barré syndrome following infection with Campylobacter jejuni. Am J Epidemiol. 2001;153:610-4.

40. Offit PA. Thimerosal and vaccines - a cautionary tale. N Engl J Med. 2007;357:1278-9.

41. Schonberger LB, Bregman DJ, Sullivan-Bolyai JZ, Keenlyside RA, Ziegler DW, Retailliau HF, et al. Guillain-Barré syndrome following vaccination in the National Influenza Immunization Program, United States, 1976-1977. Am J Epidemiol. 1979;110:105-23.

42. Hoshino T, Uchiyama Y, Ito E, Osawa S, Ohashi T. Simultaneous development of acute disseminated encephalomyelitis and Guillain-Barré syndrome associated with H1N1 09 influenza vaccination. Intern Med. 2012;51:1595-158.

43. Hughes RA, Cornblath DR. Guillain-Barré syndrome. Lancet. 2005;366:1653-66.

44. Terryberry J, Sutjita M, Shoenfeld Y, Gilburd B, Tanne D, Lorber $\mathrm{M}$, et al. Myelin- and microbe-specific antibodies in GuillianBarre syndrome. J. Clin. Lab. Analysis. 1995;9:308-19.

45. Shoenfeld Y, Isenberg D. Natural autoantibodies eds. Boca-Raton: CRC; 1993: p. 15-33.

46. Nachamkin I, Shadomy S, Moran AP, Cox N, Fitzgerald C, Ung H, et al. Anti-ganglioside antibody induction by swine (A/NJ/1976/ H1N1) and other influenza vaccines: insights into vaccine-associated Guillain-Barré syndrome. J Infect Dis. 2008;198(2):226-33.

47. Lei T, Sutjita K, Kok KH, Chan KH, Chan EY, Hung IF. Antiganglioside antibodies were not detected in human subjects infected with or vaccinated against 2009 pandemic influenza A (H1N1) virus. Vaccine. 2012;30(16):2605-10.

48. Hughes RA, Choudhary PP, Osborn M, Rees JH, Sanders EA. Immunization and risk of relapse of Guillain-Barre syndrome or chronic inflammatory demyelinating polyradiculoneuropathy. Muscle Nerve. 1996;19:1230-1.

49. Opie EL. On the relation of chronic interstitial pancreatitis to the islands of Langerhans and to diabetes melutus. J Exp Med. 1901;5:397-428. 
50. Institute for Vaccine Safety Diabetes Workshop Panel. Childhood immunizations and type 1 diabetes: summary of an Institute for vaccine safety workshop. The Institute for Vaccine Safety Diabetes Workshop Panel. Pediatr Infect Dis J. 1999;18(3):217-22.

51. Atkinson MA, Maclaren NK. The pathogenesis of insulindependent diabetes mellitus. N Engl J Med. 1994;331(21):1428-36.

52. Bach JF. The effect of infections on susceptibility to autoimmune and allergic diseases. N Engl J Med. 2002;347(12):911-20.

53. Classen DC, Classen JB. The timing of pediatric immunization and the risk of insulin-dependent diabetes mellitus. Infect Dis Clin Pract. 1997;6:449-54.

54. Classen JB. The timing of immunization affects the development of diabetes in rodents. Autoimmunity. 1996;24:137-45.

55. Institute for Vaccine Safety Diabetes Workshop Panel. Childhood immunizations and type 1 diabetes: summary of an Institute for Vaccine Safety Workshop. Pediatr Infect Dis J. 1999;18:217-22.

56. Hviid A, Stellfeld M, Wohlfahrt J, Melbye M. Childhood vaccination and type 1 diabetes. N Engl J Med. 2004;350(14):1398-404.

57. Classen JB, Classen DC. Immunization in the first month of life may explain decline in incidence of IDDM in The Netherlands. Autoimmunity. 1999;31:43-5.

58. Wynn DR, Rodriguez M, O'Fallon WM, Kurland LT. A reappraisal of the epidemiology of multiple sclerosis in Olmsted County Minnesota. Neurology. 1990;40:780-6.

59. Todd JA, Wicker LS. Genetic protection from the inflammatory disease type 1 diabetes in humans and animal models. Immunity. 2001;15:387-95.

60. DeStefano F, Verstraeten T, Jackson LA, Okoro CA, Benson P, Black SB, et al. Vaccinations and risk of central nervous system demyelinating diseases in adults. Arch Neurol. 2003;60(4):504-9.

61. Payne DC, Rose CE, Kerrison J, Aranas A, Duderstadt S, McNeil MM. Anthrax vaccination and risk of optic neuritis in the United States military, 1998-2003. Arch Neurol. 2006;63(6):871-5 .

62. Miller AE, Morgante LA, Buchwald LY, Nutile SM, Coyle PK, Krupp LB, et al. A multicenter, randomized, double-blind, placebo-controlled trial of influenza immunization in multiple sclerosis. Neurology. 1997;48(2):312-4.

63. Confavreux C, Suissa S, Saddier P, Bourdes V, Vukusic S. Vaccinations and the risk of relapse in multiple sclerosis. $\mathrm{N}$ Engl J Med. 2001;344(5):319-26.

64. Hurwitz ES, Schonberger LB, Nelson DB, Holman RC. GuillainBarré syndrome and the 1978-1979 influenza vaccine. N Engl J Med. 1981;304(26):1557-61.

65. Kaplan JE, Katona P, Hurwitz ES, Schonberger LB. Guillain-Barre syndrome in the United States, 1979-19 and 1980-1981. Lack of an association with influenza vaccination. JAMA. 1982;248(6):698-700.

66. Hughes RA, Charlton J, Latinovic R, Gulliford MC. No association between immunization and Guillain-Barre syndrome in the United Kingdom, 1992 to 2000. Arch Intern Med. 2006;166(12):1301-4.

67. Juurlink DN, Stukel TA, Kwong J, Kopp A, McGeer A, Upshur RE. Guillain-Barre syndrome after influenza vaccination in adults: a population-based study. Arch Intern Med. 2006;166(20):2217-21.

68. Greene SK, Kulldorff M, Lewis EM, Li R, Yin R, Weintraub ES, et al. Near real-time surveillance for influenza vaccine safety: proof-of-concept in the Vaccine Safety Datalink Project. Am J Epidemiol. 2010;171(2):177-88.

69. Cohen JA. The future of multiple sclerosis treatment. J Neurol Sci. 2009;277(1):S55-61.

70. Tourbah A, Gout O, Liblau R, Lyon-Caen O, Bougniot C, Iba-Zizen MT, et al. Encephalitis after hepatitis B vaccination: recurrent disseminated encephalitis or MS? Neurology. 1999;53:396-401.

71. Gout $\mathrm{O}$, Lyon-Caen $\mathrm{O}$. Sclerotic plaques and vaccination against hepatitis B. Rev Neurol (Paris). 1998;154:205-7.

72. Fourrier A, Bégaud B, Alpérovitch A, Verdier-Taillefer MH, Touzè E, Decker N, et al. Hepatitis B vaccine and first episodes of central nervous system demyelinating disorders: a comparison between reported and expected number of cases. Br J Clin Pharmacol. 2001;51:489-49.

73. Dittmann S. Special address: safety of hepatitis B vaccination. Vaccine. 2000;18:S10-1.

74. Confavreux C, Suissa S, Saddier P, Bourdès V, Vukusic S. Vaccinations and the risk of relapse in multiple sclerosis. Vaccines in Multiple Sclerosis Study Group. N Engl J Med. 2001;344:319-26.

75. Ascherio A, Zhang SM, Hernàn MA, Olek MJ, Coplan PM, Brodovicz K, et al. Hepatitis B vaccination and the risk of multiple sclerosis. N Engl J Med. 2001;344:327-32.

76. Hernàn MA, Jick SS, Olek MJ, Jick H. Recombinant hepatitis B vaccine and the risk of multiple sclerosis. Neurology; 2004; 63(5): $838-42$

77. Geier DA, Geier MR. A case-control study of serious autoimmune adverse events following hepatitis B immunization. Autoimmunity. 2005;38(4):295-301.

78. Mikaeloff Y, Caridade G, Suissa S, Tardieu M. Hepatitis B vaccine and the risk of CNS inflammatory demyelination in childhood. Neurology. 2009;72(10):873-80.

79. Terney D, Beniczky S, Barsi P, Kondàkor I, Perènyi J, Faludi B, et al. Multiple sclerosis after hepatitis B vaccination in a 16- yearold patient. Chin Med J. 2006;119(1):77-9.

80. Atlas SW. Magnetic resonance imaging of the brain and spine.3rd edition. Lippincott, Williams and Wilkins; 2003; 1-2200

81. Faure E. Multiple sclerosis and hepatitis B vaccination: could minute contamination of the vaccine by partial hepatitis $\mathrm{B}$ virus polymerase play a role through molecular mimicry? Med Hypotheses. 2005;65(3):509-20.

82. James JA, Kaufman KM, Farris AD, Taylor-Albert E, Lehman TJ, Harley JB. An increased prevalence of Epstein-Barr virus infection in young patients suggests a possible etiology for systemic lupus erythematosus. J Clin Investig. 1997;100(12):3019-26.

83. Vaughan JH. The Epstein-Barr virus and systemic lupus erythematosus. J Clin Invest. 1997;100(12):2939-40.

84. Ippolito A, Petri M. An update on mortality in systemic lupus erythematosus. Clin Exp Rheumatol. 2008;26(5 (suppl 51):S72-9.

85. Aron-Maor A, Shoenfeld Y. Vaccination and systemic lupus erythematosus: the bidirectional dilemmas. Lupus. 2001;10(3):237-40.

86. Older SA, Battafarano DF, Enzenauer RJ, Krieg AM. Can immunization precipitate connective tissue disease? Report of five cases of systemic lupus erythematosus and review of the literature. Semin Arthritis Rheum. 1999;29(3):131-9.

87. Cooper GS, Dooley MA, Treadwell EL, St Clair EW, Gilkeson GS. Risk factors for development of systemic lupus erythematosus: allergies, infections, and family history. J Clin Epidemiol. 2002;55(10):982-9.

88. Guiserix J. Systemic lupus erythematosus following hepatitis B vaccine. Nephron. 1996;74(441):1.

89. Borisova VV, Krel' VV. Systemic lupus erythematosus etiologically due to the hepatitis B and C viruses. Ter Arkh. 1992;64:92-3.

90. Agmon-Levin N, Zafrir Y, Paz Z, Shilton T, Zandman-Goddard G, Shoenfeld Y. Ten cases of systemic lupus erythematosus related to hepatitis B vaccine. Lupus. 2009;18(13):1192-7.

91. Maillefert JF, Sibilia J, Toussirot E, Vignon E, Eschard JP, Lorcerie B, et al. Rheumatic disorders developed after hepatitis B vaccination. Rheumatology (Oxford). 1999;38(10):978-83.

92. Santoro D, Stella M, Montalto G, Castellino S. Lupus nephritis after hepatitis B vaccination: an uncommon complication. Clin Nephrol. 2007;67(1):61-3.

93. Kowal C, Weinstein A, Diamond B. Molecular mimicry between bacterial and self antigen in a patient with systemic lupus erythematosus. Eur J Immunol. 1999;29(6):1901-11.

94. Hocine MN, Farrington CP, Touze E, Whitaker HJ, Fourrier A, Moreau T, et al. Hepatitis B vaccination and frst central nervous system demyelinating events: reanalysis of a case-control study 
using the self-controlled case series method. Vaccine. 2007;25(31):5938-43.

95. Vlacha V, Forman EN, Miron D, Peter G. Recurrent thrombocytopenic purpura after repeated measles-mumps-rubella vaccination. Pediatrics. 1996;97:738-9.

96. Jonville-Bera AP, Autret E, Galy-Eyraud C, Hessel L. Thrombocytopenic purpura after measles, mumps and rubella vaccination: a retrospective survey by the French regional pharmacovigilance centres and pasteurmerieux serums et vaccines. Pediatr Infect Dis J. 1996;15:44-8.

97. Cecinati V, Principi N, Brescia L, Giordano P, Esposito S. Vaccine administration and the development of immune thrombocytopenic purpura in children. Hum Vaccin Immunother. 2013;9:1158-62.

98. Izak M, Bussel JB. Management of thrombocytopenia. F1000Prime Rep. 2014;6(45).

99. Cines DB, Liebman H, Stasi R. Pathobiology of secondary immune thrombocytopenia. Semin Hematol. 2009;46(1 Suppl 2):S2-14.

100. Oski FA, Naiman JL. Effect of live measles vaccine on the platelet count. N Engl J Med. 1966;275(7):352-6.

101. Autret E,Jonville-Béra AP, Galy-Eyraud C, Hessel L. Thrombocytopenic purpura after isolated or combined vaccination against measles, mumps and rubella. Therapie. 1996;51(6):677-80.

102. Jonville-Bera AP, Autret E, Galy-Eyraud C, Hessel L. Thrombocytopenic purpura after measles, mumps and rubella vaccination: a retrospective survey by the French regional pharmacovigilance centres and pasteur-merieux serums et vaccins. Pediatr Infect Dis J. 1996;15(1):44-8.

103. Institute of Medicine (US) Vaccine Safety Committee; Stratton KR, Howe CJ, Johnston RB Jr., editors. Adverse events associated with childhood vaccines: evidence bearing on causality.1994;118-186.

104. France EK, Glanz J, Xu S, Hambidge S, Yamasaki K, Black SB, et al. Risk of immune thrombocytopenic purpura after measles-mumpsrubella immunization in children. Pediatrics. 2008;121(3):e687-92.

105. Miller E, Waight P, Farrington CP, Andrews N, Stowe J, Taylor B. Idiopathic thrombocytopenic purpura and MMR vaccine. Arch Dis Child. 2001;84(3):227-9.

106. Black C, Kaye JA, Jick H. MMR vaccine and idiopathic thrombocytopaenic purpura. Br J Clin Pharmacol. 2003;55(1):107-11.

107. Okazaki N, Takeguchi M, Sonoda K, Handa Y, Kakiuchi T, Miyahara $\mathrm{H}$, et al. Detection of platelet-binding anti-measles and anti-rubella virus IgG antibodies in infants with vaccine-induced thrombocytopenic purpura. Vaccine. 2011;29(31):4878-80.

108. Toltl LJ, Nazi I, Jafari R, Arnold DM. Piecing together the humoral and cellular mechanisms of immune thrombocytopenia. Semin Thromb Hemost. 2011;37:631-9.

109. Kuwana M, Okazaki Y, Ikeda Y. Splenic macrophages maintain the antiplatelet autoimmune response via uptake of opsonized platelets with immune thrombocytopenic purpura. J Thromb Haemost. 2009;7(2):322-9.

110. Nieminen U, Peltola H, Syrjälä MT, Mäkipernaa A, Kekomäki R. Acute thrombocytopenic purpura following measles, mumps and rubella vaccination. A report on 23 patients. Acta Paediatr. 1993;82(3):267-70.

111. British Committee for Standards in Haematology General Haematology Task Force. Guidelines for the investigation and management of idiopathic thrombocytopenic purpura in adults, children and in pregnancy. Br J Haematol. 2003;120(4):574-96.

112. Raychaudhuri S, Thomson BP, Remmers EF, Eyre S, Hinks A, Guiducci C, et al. Genetic variants at CD28, PRDM1 and CD2/ CD58 are associated with rheumatoid arthritis risk. Nat Genet. 2009;41(12):1313-8.

113. Cerhan JR, Saag KG, Merlino LA, Mikuls TR, Criswell LA. Antioxidant micronutrients and risk of rheumatoid arthritis in a cohort of older women. Am J Epidemiol. 2003;157(4):345-54.
114. Plenge RM, Seielstad M, Padyukov L, Lee AT, Remmers EF, Ding $\mathrm{B}$, et al. TRAF1-C5 as a risk locus for rheumatoid arthritis - a genomewide study. N Engl J Med. 2007;357(12):1199-209.

115. Grasland A, Vinceneux P. Rheumatic manifestations of vaccination. R Rheumat Eur. 1999;28:25-7.

116. Nussinovitch M, Harel L, Varsano I. Arthritis after mumps and measles vaccination. Arch Dis Child. 1995;72(4):348-9.

117. Benjamin CM, Chew CG, Silman AJ. Joint and limb symptoms in children after immunization with measles, mumps and rubella vaccine. BMJ. 1992;304:1075-7.

118. Slater PE, Ben-Zvi T, Fogel A, Ehrenfeld M, Ever-Hadani S. Absence of an association between rubella vaccination and arthritis in underimmune postpartum women. Vaccine. 1995;13(16):1529-32.

119. Tingle AJ, Mitchell LA, Grace M, Middleton P, Mathias R, MacWilliam L, et al. Randomised double-blind placebo-controlled study on adverse effects of rubella immunisation in seronegative women. Lancet. 1997;349(9061):1277-81.

120. Ray P, Black S, Shinefeld H, Dillon A, Schwalbe J, Holmes S, et al. Risk of chronic arthropathy among women after rubella vaccination. J Am Med Assoc. 1997;278(7):551-6.

121. Mitchell LA, Tingle AJ, MacWilliam L, Home C, Keown P, Gaur LK, et al. HLA-DR class II associations with rubella vaccineinduced joint manifestations. J Infect Dis. 1998;177(1):5-12.

122. Peltola H, Heinonen OP. Frequency of true adverse reactions to measles-mumps-rubella vaccine. Lancet. 1986;327(8487):939-42.

123. Virtanen M, Peltola H, Paunio M, Heinonen OP. Day-to-day reactogenicity and the healthy vaccinee effect of measlesmumps-rubella vaccination. Pediatrics 2000;106(5):E62

124. dos Santos BA, Ranieri TS, Bercini M, Schermann MT, Famer S, Mohrdieck R, et al. An evaluation of the adverse reaction potential of three measles-mumps-rubella combination vaccines. Rev Panam Salud Publica. 2002;12(4):240-6.

125. Pattison E, Harrison BJ, Griffths CEM, Silman AJ, Bruce IN. Environmental risk factors for the development of psoriatic arthritis: results from a case-control study. Ann Rheum Dis. 2008;67(5):672-6.

126. Blom L, Nystrom L, Dahlquist G. The Swedish childhood diabetes study. Vaccinations and infections as risk determinants for diabetes in childhood. Diabetologia. 1991;34(3):176-81.

127. Altobelli E, Petrocelli R, Verrotti A, Valenti M. Infections and risk of type I diabetes in childhood: a population-based case-control study. Eur J Epidemiol. 2003;18(5):425-30.

128. Pellegrino P, Carnovale C, Perrone V, Salvati D, Gentili M, Brusadelli T, Pozzi M, Antoniazzi S, Clementi E, Radice S. On the association between human papillomavirus vaccine and primary ovarian failure. American Journal of Reproductive Immunology. Am J Reprod Immunol. 2014;71:293-4.

129. Colafrancesco S, Perricone C, Tomljenovic L, Shoenfeld Y. Human papilloma virus vaccine and primary ovarian failure: another facet of the autoimmune/inflammatory syndrome induced by adjuvants. Am J Reprod Immunol. 2013;70:309-16.

130. Gatto M, Agmon-Levin N, Soriano A, Manna R, Maoz-Segal R, Kivity S, et al. Human papillomavirus vaccine and systemic lupus erythematosus. Clin Rheumatol. 2013;32:1301-7.

131. Macartney KK, Chiu C, Georgousakis M, Brotherton JM. Safety of human papillomavirus vaccines: a review. Drug Saf. 2013;36: 393-412.

132. Cojocaru M, Chicos B. ASIA or Shoenfeld's syndrome - an autoimmune syndrome induced by adjuvants. Rom J Intern Med. 2013;51(3-4):131-4.

133. Israeli E, Agmon-Levin N, Blank M, Shoenfeld Y. Adjuvants and autoimmunity. Lupus. 2009;18(13):1217-25.

134. Agmon-Levin N, Hughes GR, Shoenfeld Y. The spectrum of ASIA: 'autoimmune (auto-inflammatory) syndrome induced by adjuvants'. Lupus. 2012;21(2):118-20.

135. Vera-Lastra O, Medina G, Cruz-Dominguez Mdel P, Jara LJ, Shoenfeld Y. Autoimmune/inflammatory syndrome induced by 
adjuvants (Shoenfeld's syndrome): clinical and immunological spectrum. Expert Rev Clin Immunol. 2013;9(4):361-73.

136. Marrack P, McKee AS, Munks MW. Towards an understanding of the adjuvant action of aluminium. Nat Rev Immunol. 2009;9(4):287-93.

137. McKee AS, Munks MW, MacLeod MK, Fleenor CJ, Van Rooijen $\mathrm{N}$, Kappler JW, et al. Alum induces innate immune responses through macrophage and mast cell sensors, but these sensors are not required for alum to act as an adjuvant for specific immunity. $\mathrm{J}$ Immunol. 2009;183(7):4403-14.

138. Soriano A, Nesher G, Shoenfeld Y. Predicting post-vaccination autoimmunity: who might be at risk? Pharmacol Res. 2015;92:18-22.

139. Palmieri B, Poddighe $\mathrm{D}$, Vadalà $\mathrm{M}$, Laurino $\mathrm{C}$, Carnovale $\mathrm{C}$, Clementi E. Severe somatoform and dysautonomic syndromes after HPV vaccination: case series and review of literature. Immunol Res. 2017;65(1):106-16.

140. Poddighe D, Vadalà M, Laurino C, Palmieri B. Somatoform and neurocognitive syndromes after HPV immunization are not associated to cell-mediated hypersensitivity to aluminum. Toxicol In vitro. 2017; 43:58-61

141. Garcia Allende N, Garcia Posada MJ, Radosta MF, Sánchez AV, Mayer Wolf M, Rodriguez V. Acute transverse myelitis in a traveler. Medicina (B Aires). 2016;76(4):242-4.

142. Karussis D, Petrou P. The spectrum of post-vaccination inflammatory CNS demyelinating syndromes. Autoimmun Rev. 2014;13(3):215-24.

143. Sutton I, Lahoria R, Tan I, Clouston P, Barnett M. CNS demyelination and quadrivalent HPV vaccination. Mult Scler. 2009;15(1):116-9.

144. Poland GA, Ovsyannikova IG, Jacobson RM. Personalized vaccines: the emerging field of vaccinomics. Expert Opin Biol Ther. 2008;8(11):1659-67.

145. Poland GA, Ovsyannikova IG, Jacobson RM. Adversomics: the emerging field of vaccine adverse event immunogenetics. Pediatr Infect Dis J. 2009;28(5):431-2.

146. Stern LJ, Calvo-Calle JM. HLA-DR: molecular insights and vaccine design. Curr Pharm Des. 2009;15(28):3249-61.

147. Reif M, McKinney BA, Motsinger AA, Chanock SJ, Edwards KM, Rock MT, et al. Genetic basis for adverse events after smallpox vaccination. J Infect Dis. 2008;198(1):16-22.

148. Mangan DF, Robertson B, Wahl SM. IL-4 enhances programmed cell death (apoptosis) in stimulated human monocytes. J Immunol. 1992;148(6):1812-6.

149. Soruri A, Kiafard Z, Dettmer C, Riggert J, Kohl J, Zwirner J. IL-4 downregulates anaphylatoxin receptors in monocytes and dendritic cells and impairs anaphylatoxin-induced migration in vivo. $\mathrm{J}$ Immunol. 2003;170:3306-14.

150. Janeway CA, Travers P, Walport M, Shlomchik MJ. Immunobiology: The immune system in health and disease, vol. 5. 5th ed. New York: Garland Publishing; 2001.

151. Goodbourn S, Didcock L, Randall RE. Interferons: cell signalling, immune modulation, antiviral response and virus countermeasures. J Gen Virol. 2000;81(Pt 10):2341-64.
152. Dedoussis GV, Panagiotakos DB, Pitsavos C, Chrysohoou C, Skoumas J, Choumerianou D, et al. An association between the methylenetetrahydrofolate reductase (MTHFR) C677T mutation and inflammation markers related to cardiovascular disease. Int $\mathrm{J}$ Cardiol. 2005;100(3):409-14.

153. Urano W, Taniguchi A, Yamanaka H, Tanaka E, Nakajima H, Matsuda Y, et al. Polymorphisms in the methylenetetrahydrofolate reductase gene were associated with both the efficacy and the toxicity of methotrexate used for the treatment of rheumatoid arthritis, as evidenced by single locus and haplotype analyses. Pharmacogenetics. 2002;12(3):183-90.

154. Lerner A. Aluminum as an adjuvant in Crohn's disease induction. Lupus. 2012;21(2):231-8.

155. Dimitrijevic L, Živković I, Stojanović M, Petrušić V, ŽivančevićSimonović S. Vaccine model of antiphospholipid syndrome induced by tetanus vaccine. Lupus. 2012;21(2):195-202.

156. Vista ES, Crowe SR, Tompson LF, Air GM, Robertson JM, Guthridge JM, et al. Influenza vaccination can induce new-onset anticardiolipins but not 2-glycoprotein-I antibodies among patients with systemic lupus erythematosus. Lupus. 2012;21(2):168-74.

157. Shoenfeld Y, Agmon-Levin N. "ASIA" - autoimmune/inflammatory syndrome induced by adjuvants. J Autoimmun. 2011;36(1):4-8.

158. Gaspar LP, Mendes YS, Yamamura MY, Almeida LF, Caride E, Gonçalves RB, et al. Pressure-inactivated yellow fever 17DD virus: implications for vaccine development. J Virol Methods. 2008;150(1-2):57-62.

159. Monath TP, Fowler E, Johnson CT, Balser J, Morin MJ, Sisti M, et al. An inactivated cell culture vaccine against yellow fever. $\mathrm{N}$ Engl J Med. 2011;364(14):1326-33.

160. Singh B. Stimulation of the developing immune system can prevent autoimmunity. Autoimmunity. 2000;14:15-22.

161. Gross DM, Forsthuber T, Tary-Lehmann M, Etling C, Ito K, Nagy $\mathrm{ZA}$, et al. Identification of LFA-1 as a candidate autoantigen in treatment-resistant Lyme arthritis. Science. 1998;281:703-6.

162. Chen RT, Pless R, Destefano F. Epidemiology of autoimmune reactions induced by vaccination. J Autoimmun. 2001;16:309-18.

163. van Assen S, Agmon-Levin N, Elkayam O, Cervera R, Doran MF, Dougados M. EULAR recommendations for vaccination in adult patients with autoimmune inflammatory rheumatic diseases. Ann Rheum Dis. 2011;70(3):414-22.

164. Bizzaro N, Tozzoli R, Shoenfeld Y. Are we at a stage to predict autoimmune rheumatic diseases. Arthritis Rheum. 2007;56:1736-44.

165. Jacobson EM, Tomer Y. The CD40, CTLA-4, thyroglobulin, TSH receptor and PTPN22 gene quintet and its contribution to thyroid autoimmunity: back to the future. J Autoimmun. 2007;28:85-98.

166. Golubnitschaja O, Baban B, Boniolo G, Wang W, Bubnov R, Kapalla M, et al. Medicine in the early twenty-first century: paradigm and anticipation-EPMA position paper 2016. EPMA J. 2016;7:23. 